\title{
Sistem Pemantauan Suhu dan Kelembaban Ruangan Secara Real-Time Berbasis Web Server
}

\author{
Prasetyo Y ${ }^{1}$ Ivan P S ${ }^{2}$ Qisthi Al Hazmi HR. ${ }^{3}$ \\ 1,2 Jurusan Teknik Telekomunikasi, IT Telkom Purwokerto \\ ${ }^{3}$ Universitas Pembangunan Nasional Veteran Jakarta \\ Email : ${ }^{1}$ Prasetyo@ittelkom-pwt.ac.id , ${ }^{2} 17101020 @$ ittelkom-pwt.ac.id, \\ ${ }^{3}$ qisthialhazmi@upnvj.ac.id
}

\begin{abstract}
Abstrak: Dunia IoT(internet of things) semakin berkembang pesat dan banyak diminati dalam aplikasi sistem kendali khususnya mikrokontroler. Dalam era sekarang ini mikrokontroler yang paling banyak digunakan adalah arduino. Salah satu nya yaitu microcontroler yang terhubung dengan sensor suhu ruangan dan kelembaban. Namun, banyak kasus tidak efisiennya sistem pemantauan yang dilakukan secara real time dan informasi yang ditampilkan tidak sedetail mungkin. Ada beberapa metode yang digunakan untuk mengakses pemantauan suhu dan kelembaban ruangan salah satunya berbasis web server. Web server ini berfungsi sebagai database untuk menerima dan mengirimkan data dari nodeMCU yang sudah terhubung dengan sensor. Terdapat 2 data sensor yang dikirim bersama secara real time yang nantinya dapat dipantau secara langsung pada web server. Berdasarkan hasil penelitian, 2 data sensor yang dikirimkan dapat disimpan dalam database dalam satuan waktu yang sama.
\end{abstract}

Kata Kunci: IoT, NodeMCU, Sensor Suhu dan Kelembaban, Web Server

\begin{abstract}
The internet of things is growing rapidly and is in great demand in the application of control systems, especially microcontrollers. In the current era the most widely used microcontroller is Arduino. One of them is a microcontroller that is connected with a room temperature sensor and humidity. However, there are many cases of inefficient monitoring systems carried out in real time and the information displayed is not as detailed as possible. There are a number of methods used to access room temperature and humidity monitoring, one of which is web server based. This web server functions as a database to receive and send data from nodeMCU that is already connected to the sensor. There are 2 sensor data that are sent together in real time which can be monitored directly on the web server. Based on the results of the study, 2 sensor data sent can be stored in the database in the same time unit.
\end{abstract}

Keywords: IoT, NodeMCU, Temperature Sensors and Humidity, Web Server

\section{PENDAHULUAN}

Web server, untuk berkomunikasi dengan clientnya mempunyai protocol sendiri yaitu HTPP (Hypertext Transfer Protocol). Dengan protocol ini, komunikasi antara web server dengan client dapat saling mengerti dan lebih mudah. Mayoritas pengguna internet lebih familiar menggunakan format HTML (Hypertext Markup Lenguage) karena penggunaanya lebih sederhana dan mudah dimengerti, karena client dapat mengakses atau memebuka dokumen (database) dari web server.
Web server merupakan software yang melayani permintaan HTPP atau HTPPS dari browser dan mengirimkannya kembali dalam bentuk halaman-halaman web. Proses yang dimulai dari permintaan web client kemudian diterima oleh web server dan dikembalikan hasil prosesnya oleh web server ke web client lagi dilakukan secara transparan, sehingga setiap client dapat dengan mudah mengetahui tiap-tiap prosesnya.

\footnotetext{
Internet of Things (IoT)

Internet of Things (IoT) adalah konsep yang menghubungkan semua perangkat ke 
internet dan memungkinkan perangkat IoT dapat berkomunikasi satu sama lain melalui internet. Teknologi Internet of Things(IoT) memberikan peluang untuk menciptakan suatu aplikasi atau layanan yang sangat bermanfaat[1]. IoT merupakan jaringan raksasa dari perangkat yang terhubung semua yang mengumpulkan dan membagikan data tentang bagaimana suatu perangkat tersebut digunakan dan lingkungan dimana perangkat tersebut di operasikan. contoh penerapan IoT pada paper kali ini yaitu sensor suhu dan sensor kelembaban ruangan mengumpulkan data dan mengirimkannya melalui jaringan internet dan menampilkan datanya pada web server[2]. DHT11 adalah jenis sensor yang dapat mendeteksi suhu dan kelembaban atmosfernya yang dekat dan tersedia di hampir semua tempat di Dunia[3].

\section{NodeMCU}

Node MCU merupakan sebuah papan mikrokontroller yang berbasis modul WiFi ESP8266, sehingga sesuai untuk diterapkan di bidang Internet of Things (IoT), smart home control atau aplikasi pengendalian tanpa kabel lainnya[4]. Node MCU merupakan platform IoT yang bersifat Opensource, memiliki firmware untuk menjalankan sistem Wi-Fi ESP8266 modul chip. Firmware menggunakan Bahasa LUA Scripting. Menggunakan Arduino IDE, Node MCU bias diprogram. Dengan menginstal driver papan ESP8266 dari opsi manajer papan atau sumber web, Node MCU dapat diprogram dari Arduino IDE. Node MCU memiliki 128 Kbytes of Memory dan menggunakan Sistem Operasi Pengujian eXtendable (XTOS). Node MCU adalah papan pengembangan IoT yang sangat murah dibandingkan dengan Intel Galileo, Raspberry $\mathrm{Pi}$, UDOO, dan papan pengembangan IoT lainnya[5].

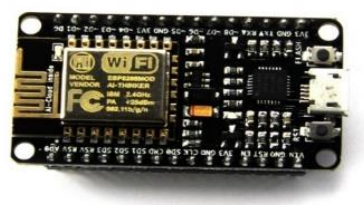

Gambar 1. Node MCU ESP 12E[2].

\section{Sensor Suhu dan Kelembaban}

Sensor suhu dan kelembaban yang dilakukan pada penelitian ini adalah DHT11 temperature and humidity sensor. DHT11 merupakan sensor digital untuk mengukur suhu dan kelembaban udara di sekitarnya. Sensor ini memiliki tingkat stabilitas yang sangat baik dengan fitur kalibrasi yang sangat akurat.Walaupun ukurannya kecil, sensor ini mampu mentransmisikan sinyal hingga 20 meter. Sensor. DHT11 merupakan sensor digital yang dapat mendeteksi suhu dan kelembaban suatu ruangan[5].

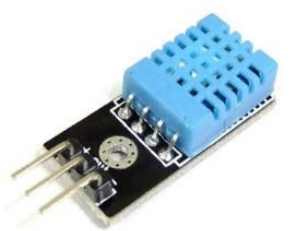

Gambar 2. DHT11 temperature and humadity sensor [6].

Sensor ini membutuhkan suplai voltase +5 volt. Pengukuran temperature oleh alat ini berkisar antara $0-50 \mathrm{C}$, dengan eror $\pm 2 \mathrm{C}$. Sedangkan pada pengukuran 12 kelembaban berkisar antara $20-90 \% \mathrm{RH}$, dengan eror \pm 5 $\%$ RH. Dimana data luaran yang didapatkan merupakan data digital[6]. Suhu dan kelembaban merupakan dua objek pengukuran yang acapkali terdapat di dalam sistem akuisisi data. Terdapat banyak piranti sensor yang berfungsi untuk mengukur dua objek tersebut dan akurasi merupakan salah satu parameter yang dapat digunakan untuk memilihnya.

\section{METODE PENELITIAN}

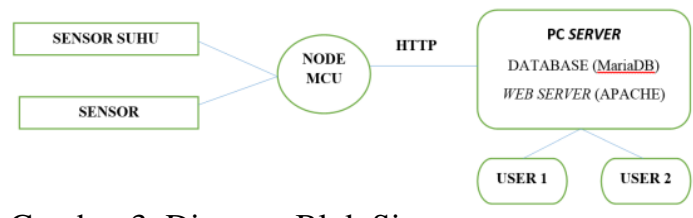

Gambar 3. Diagram Blok Sistem

Berdasarkan Gambar 3 dalam blok diagram sistem terdapat dua sensor, yaitu sensor suhu dan sensor kelembaban. Kedua sensor ini yang nantinya akan membaca data berupa suhu dan kelembaban yang nantinya akan dikirim melalui sebuah node MCU. Dalam Node MCU ini data akan diolah yang kemudian dikirim ke PC server. Fungsi dari PC server ini mengolah data yang telah dibaca oleh sensor dan diproses oleh node MCU dengan menjadikannya sebuah database. Database (MariaDB) ini yang nantinya akan diproses oleh web server (Apache), sehingga web server dapat memberi akses informasi kepada client yang membutuhkan informasi. Database yang disajikan oleh web server nanti akan berupa tabel 
dengan perubahan suhu dan kelembaban secara real time dan berubah setiap beberapa detik sekali (sesuai dengan delay yang ditetapkan oleh server). Setiap client dapat mengakses sistem pemantau suhu dan kelembaban dari server dengan mengakses jaringan yang sama dengan server dan mengetahui alamat web server.

\section{HASIL DAN ANALISA}

Pada penelitian mengenai sistem pemantauan suhu dan kelembaban ruangan secara real time berbasis web server ini, memberikan sebuah data-data dari suhu dan kelembabannya di suatu ruangan secara real time yang mana data-data suhu dan kelembaban suatu ruangan tersebut ditampilkan didalam web server (Apache). Sistem pemantauan suhu dan kelembaban pada ruangan ini membutuhkan Node MCU, sensor DHT 11, Add3.php, software Arduino, Notepad++, dan software XAMPP.

Node MCU dibutuhkan untuk menghubungkan pada internet (Connected to Internet), dimana nantinya Internet ini digunakan untuk sebagai penyaluran hasil data-data suhu dan kelembaban suatu ruangan yang dihasilkan oleh Node MCU yang telah dipasang sensor DHT11 untuk ditampilkan ke server (Laptop) kita dengan cara menghubungkannya melalui Internet makanya butuh yang namanya Node MCU. Selain Node MCU berfungsi untuk mengkoneksi ke Internet, Node MCU juga berfungsi didalam penelitian ini untuk membaca sensor DHT 11, mengirimkan data dari sensor DHT 11 ke add3.php (server), dan mengirimkan data suhu dan kelembaban di sensor DHT $11 \mathrm{ke}$ server, dalam sending data dari Node MCU ke server (Laptop) dibutuhkan juga yang namanya HTTP. Sensor DHT 11 ini digunakan sebagai sensor untuk menangkap atau mengambil datadata mengenai suhu dan kelembaban di suatu ruangan. Add3.php ini berfungsi sebagai pengambil nilai atau data-data dari sensor DHT11 ini, lalu membuat sebuah tampilan berupa tabel yang berguna untuk menampilkan hasil atau data-data dari DHT 11 di data base atau pada server nantinya. Software Arduino berfungsi sebagai tempat penulisan script pemograman arduino untuk sending data dari Node MCU (DHT 11) ke Server (Laptop). Notepad ++ berfungsi sebagai tempat penulisan script Add3.php untuk menyisipkan data ke tabel didalam data base (server). Dan software XAMPP berfungsi untuk menjalankan server atau phpmyadmin untuk melihat hasil dari datadata suhu dan kelembaban suatu ruangan yang telah berhasil di sending data atau hasilnya dari Node MCU (DHT 11) ke server (Laptop) dengan menggunakan IP (Internet Protocol).

Dalam penelitian pemantauan suhu dan kelembaban suatu ruangan secara real time berbasis web server ini, Node MCU harus sudah dipasang sensor DHT 11 nya dan juga kabel jumper sudah dipasang ke pin D2 dan CN2 lalu kabel dari Node MCU dihubungkan ke port Laptop, seperti pada Gambar 4.

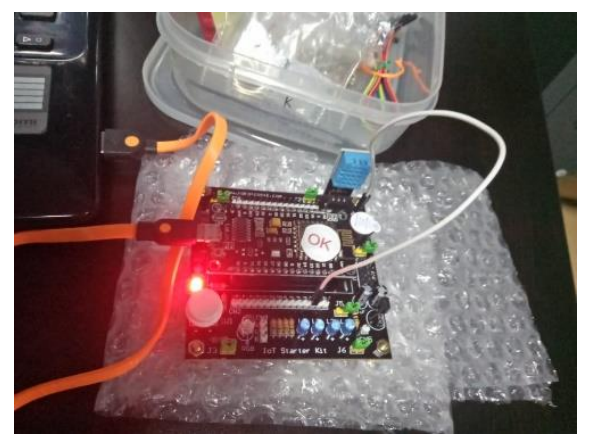

Gambar 4. Rangkaian Node MCU.

Setelah Node MCU dirangkai seperti diatas langkah selanjutnya mencoba untuk mengirimkan data atau hasil dari sensor DHT 11 yang berisi data-data suhu dan kelembaban di suatu ruangan ke server (laptop) tersebut dengan menggunakan script Arduino sending data, syarat data dari sensor DHT 11 yang terpasang di Node MCU itu dapat masuk kedalam server (laptop), didalam script Arduino alamat IP yang dimasukkan harus sesuai dengan Server (Laptop). Apabila alamat IP yang dimasukkan kedalam script Arduino berbeda, makan sending data sendor DHT 11 ke server (Laptop) akan gagal. Aktifitas sending data ini juga membutuhkan adanya koneksi WIFI atau internet. Lalu didalam script Arduino kita deklarasikan suhu (t) dan kelembaban (h) dengan tipe data float dan juga deklarasikan \#define DHTPIN D2 dengan \#define DHTTYPE DHT 11. Lalu pada void setup berisi tentang mengkoneksikan ke suatu Wi-Fi karena sending data ini mebutuhkan koneksi sebuah Wi-Fi.

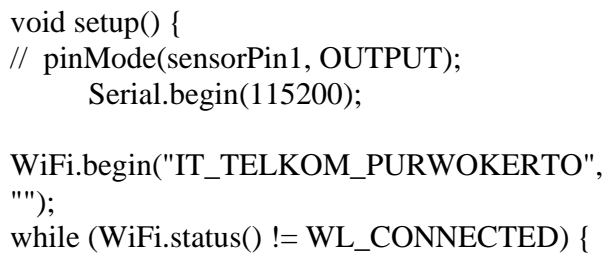


Fungsi void loop berisikan proses memasukkan variabel $\mathrm{t}$ untuk suhu dan $\mathrm{h}$ untuk kelembaban dan pengiriman data suhu (t) dan kelembaban (h) ke Server (Laptop) dan sistemnya data suhu dan kelembaban dikirimkan secara bersamaan ke server (Laptop). Untuk script didalam void loop yang harus diperhatikan pada saat memasukkan variabel $\mathrm{t}$ (suhu) dan $\mathrm{h}$ (kelembaban), karena script ini bagian penting dari pengiriman data suhu (t) dan kelembaban (h) yang akan dikirimkan secara bersamaan dari sensor DHT 11 ke server (Latop):

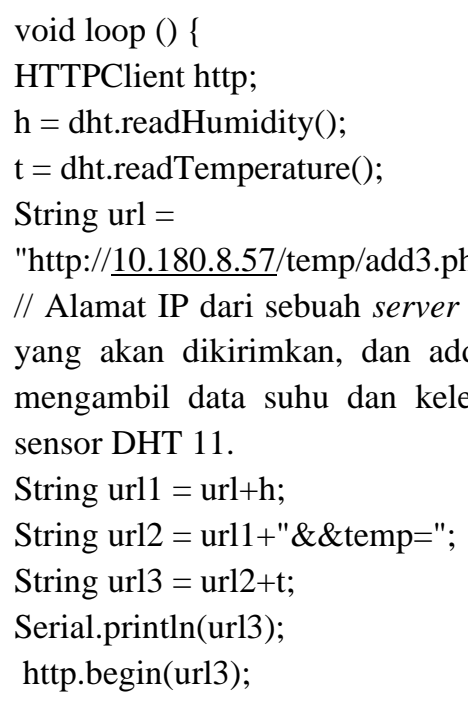

Setelah program Arduino telah selesai dibuat, lalu langkah selanjutnya adalah verify dan Upload dan apabila verify dan Upload berhasil, lakukan pengecekan di bagian serial monitor untuk mengecek apakah sending data suhu (t) dan kelembaban (h) sudah berhasil dikirimkan ke server (Laptop). Apabila berhasil tampilan di serial monitornya adalah seperti Gambar 5.

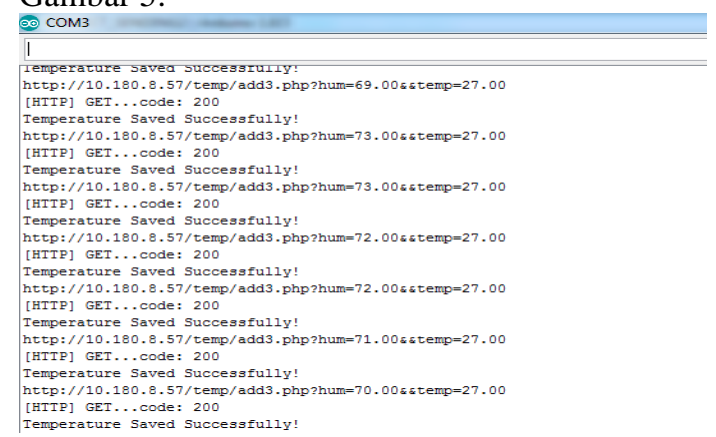

Gambar 5. Serial Monitor Arduino.
Dapat dilihat pada serial monitor Gambar 5 menandakan bahwa sending data suhu (t) dan kelembaban (h) telah berhasil dikirimkan dari NodeMCU/Arduino ke alamat IP server (Laptop).

Setelah data sensor dikirimkan ke server melalui jaringan wi-fi, data tersebut akan disimpan oleh basis data server yang di dalam basis data tersebut terdapat empat kolom di dalamnya, yaitu id, hum, temp, dan day. Gambar 6 di bawah menunjukkan bahwa data suhu (temp) dan kelembaban (hum) telah diterima oleh server dan disimpan di dalam basis data server. Kolom day pada basis data tersebut digunakan untuk menunjukkan waktu dari sistem tersebut, jadi setiap ada data dari sensor yang masuk ke dalam server, server akan merekam waktu saat sensor membaca suhu dan kelembaban ruangan dan menyimpannya di basis data server. Hal ini menunjukkan bahwa sistem bekerja secara real-time.

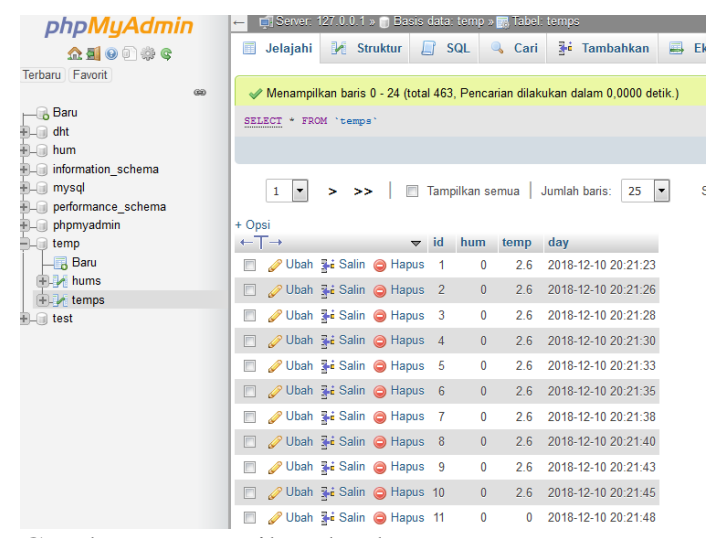

Gambar 6. Tampilan database temp.

Tabel hums dan tabel temps dapat muncul seperti gambar 6, karena adanya program php yang berfungsi menyisipkan data ke tabel pada database server tersebut.

Setelah tabel temps dan hums muncul beserta data-datanya, maka proses sending data dari sensor DHT 11 ke server (laptop) kemudian datanya ditampilkan melalui web server telah sukses diproses, selanjutnya tinggal pemantauan data suhu dan kelembaban di ruangan tersebut. Gambar 7 merupakan hasil data suhu (t) dan kelembaban (h). 


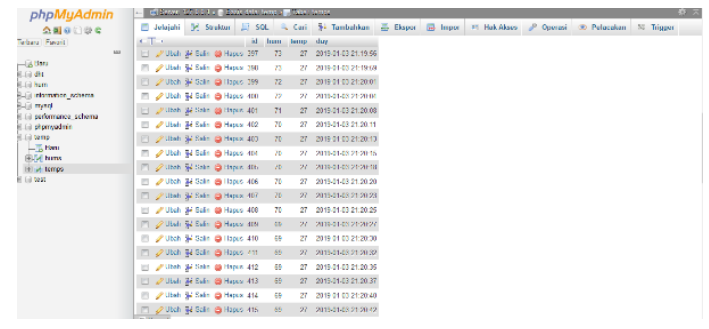

Gambar 7. hasil data suhu (t) dan kelembaban (h) pada web server.

\section{KESIMPULAN}

Berdasarkan penelitian yang telah dilakukan mengenai "Sistem pemantauan suhu dan kelembaban ruangan secara real-time berbasis web server" dapat disimpulkan bahwa sistem pemantauan suhu dan kelembaban ini dapat berfungsi dengan baik, yang ditunjukkan dengan data suhu dan kelembaban yang dikirim oleh sensor DHT11 ke web server diterima dan disimpan di basis data pada server tersebut. Pada sistem ini, data yang sudah tersimpan ke dalam basis data dapat selanjutnya ditampilkan ke dalam laman antarmuka web, baik berupa grafik atau tabel yang tujuannya untuk menunjukkan perubahan suhu dan kelembaban suatu ruangan dalam kurun waktu tertentu secara real-time.

\section{DAFTAR PUSTAKA}

[1] R. Habibi, "Teknologi Internet of Things pada STMIK BINA PATRIA," Transformasi, vol. XIII, no. 1, p. 1, 2017.

[2] M. Shidiq, "Pengertian Internet of Things (IoT)," 2 June 2018. [Online]. Available: http://otomasi.sv.ugm.ac.id/2018/06/02/pen gertian-internet-of-things-iot/. [Accessed 13 Desember 2018].

[3] Z. hasan, "Monitoring food storage humidity and temperature data using IoT," MedCrave, vol. VI, no. 4, pp. 400-404, 2018.

[4] J. Mada, "Pengertian Node MCU," 2 July 2016. [Online]. Available: http://www.madajimmy.com/artikel/proyek /69-node-mcu-esp8266-dan-papaninformasi-berbasis-max7219-.html. [Accessed 16 Desember 2018].

[5] P. Mandarani, "Perancangan dan Implementasi user interface berbasis web monitoring suhu dan kelembaban pada ruangan berbeda," TEKNOIF, vol. II, no. 2, pp. 37-42, 2 Oktober 2014.
[6] Husein, "Pengertian Akuisisi Data," 14 Maret 2010. [Online]. Available: http://digilib.unila.ac.id/5403/14/BAB\%20I I.pdf. [Accessed 16 Desember 2018]. 